\title{
PENINGKATAN POTENSI WILAYAH DAN KESEHATAN MENUJU DESA SEJAHTERA DI GIRIPANGGUNG, TEPUS, GUNUNGKIDUL
}

\author{
Fitri Merawati dan mahasiswa KKN Reguler devisi VII B \\ Universitas Ahmad Dahlan Yogyakarta \\ E-mail: fitri.merawati@pbsi.uad.ac.id
}

\begin{abstract}
Abstrak
Kuliah Kerja Nyata (KKN) merupakan program kegiatan yang wajib dilaksanakan oleh setiap mahasiswa, khusunya mahasiswa Universitas Ahmad Dahlan. Hal ini dimaksudkan agar mahasiswa maтрu belajar dari masyarakat, berbagi ilmu kepada masyarakat, dan bisa berdampingan dengan baik bersama masyarakat. KKN UAD periode LXI yang berada di Dusun Klopoloro 1, Dusum Klopoloro 2, dan Susun Bolang, Desa Giripanggung, Kecamatan Tepus, Gunungkidul kali ini mengusung tema "Peningkatan Potensi Wilayah dan Kesehatan Menuju Desa Sejahtera". Tema ini menunjukkan bahwa tujuan utama kehadiran KKN di dusun tersebut adalah ingin mengajak masyarakat berpola pikir maju dengan mengedepankan potensi wilayah dan kesehatan sehingga diharapkan nantinya akan tercipta kesejahteraan. Tujuan ini memerlukan gerakan-gerakan nyata pada masyarakat. Oleh karena itu, untuk menunjang terwujudnya tujuan tersebut mahasiswa KKN UAD mengusung program-program yang berkaitan dengan pengembangan potensi wilayah dan kesehatan seperti 1) pelatihan mocaf, 2) penyuluhan kesehatan, dan 3) pendampingan posyandu.
\end{abstract}

Kata kunci: potensi wilayah, Giripanggung, desa sejahtera

\begin{abstract}
Community Service is a compulsory program followed by every student, especially students of Universitas Ahmad Dahlan. Through this program, it is expected that the students are able to learn from the community, to share knowledge to the public, and can adjoin well with the community. The theme of Community Service UAD in the period of LXI which is located in Klopoloro 1, Klopoloro 2, and Bolang sub village, Giripanggung Village, Tepus sub District, Gunungkidul is "Improving Regional Potential and Health towards Prosper Village". This theme shows that the main purpose of the presence of Community Service in the sub villages is like to invite the community to be broad-minded by prioritizing regional potential and health so that it is expected to create prosperity in the future. This objective requires real movements in community. Therefore, to support the realization of these goals, students of Community Service UAD carry some programs related to the potential development of the region and health such as 1) mocaf training, 2) health education, and 3) Posyandu (Integrated Health Service post) assistance.

Keywords: regional potential, Giripanggung, prosper village
\end{abstract}




\section{A. PENDAHULUAN}

Univesitas Ahmad Dahlan sebagai salah satu univesitas swasta di Yogyakarta memiliki program pengabdian kepada masyarakat yang dilaksanakan melalui KKN. KKN UAD merupakan media pembelajaan bagi mahasiswa untuk mengabdi dan menerapkan ilmu yang sudah didapatkan selama kuliah. Mahasiswa KKN tidak hanya dituntut untuk berpartisipasi dalam kegiatan pengabdian masyarakat, namun diharapkan mampu memberdayakan masyarakat meningkatkan SDM maupun SDA serta bersama belajar membangun akhlaqul karimah yang lebih baik.

KKN UAD periode LXI kali ini dilaksanakan oleh mahasiswa selama sebulan yaitu mulai tanggal 24 Januari hingga 22 Februari 2017 di Kecamatan Tepus, Gunungkidul. Lokasi KKN terbagi menjadi 2 desa dengan 24 dusun. Desa Giripanggung menjadi salah satu desa di Kecamatan Tepus yang menjadi lokasi pelaksanaan KKN yang di antaranya terdapat di Dusun Klapaloro I, Klapaloro II, dan Bolang. Ketiga dusun ini memiliki persamaan penduduk yang sebagian besar sebagai petani dan peternak.

Potensi masyarakat yang sebagian besar petani dan peternak tersebut menjadi latar belakang bagi para mahasiswa KKN yang bejumlah 27 mahasiswa untuk menyusun rangkaian program. Oleh karena itu, mahasiswa mengusung tema "Peningkatan Potensi Wilayah dan Kesehatan Menuju Desa Sejahtera”.

Beberapa permasalahan yang ditemukan di ketiga dusun ini adalah: 1). Banyaknya potensi alam berupa singkong (mocaf) namun belum dikelola dengan baik, 2) Kurangnya kesadaran masyarakat tentang pentingnya deteksi kesehatan sejak dini, 3) Kurangnya perhatian masyarakat terhadap pemeriksaan perkembangan tumbuh anak. Oleh karena itu, program-program yang diusung untuk mewujudkan program tersebut adalah dengan menyelenggarakan 1) pelatihan mocaf, 2) penyuluhan kesehatan, 3) dan pendampingan posyandu.

Peran serta masyarakat menjadi faktor utama untuk mencapai tujuan yang dicitakan. Tanpa adanya peran serta masyarakat program yang dibuat tidak akan dapat berjalan lancar.

\section{B. METODE PELAKSANAAN}

Tujuan yang diharapkan program KKN di Giripanggung dilakukan dengan pemberdayaan masyarakat melalui pendidikan masyarakat, difusi ilmu pengetahuan dan teknologi dan praktek langsung.

Pendidikan masyarakat menurut Notoatmodjo merupakan pendidikan yang dapat membawa akibat terhadap perubahan perilaku sasaran. Kegiatan atau usaha untuk menyampaikan pesan kesehatan kepada masyarakat, kelompok atau individu. Dengan harapan bahwa dengan adanya pesan tersebut, masyarakat, kelompok atau individu dapat memperoleh pengetahuan tentang kesehatan yang lebih baik

Difusi menurut Roger (1985) adalah proses berkomunikasi melalui strategi yang terencana dengan tujuan untuk diadopsi. Tujuan akhir yang ingin dicapai ialah untuk terjadinya perubahan. Pengertian difusi dari Rogers yaitu "as the process by which an innovation is communicated through certain channels over time among the members of a social system". 
Diterbitkan oleh Lembaga Pengabdian kepada Masyarakat

Universitas Ahmad Dahlan Yogyakarta

Praktik langsung bertujuan agar masyarakat dapat langsung mengaplikasikan dan merasakan dampak atau perubahan dari program yang dilaksanakan.

\section{HASIL, PEMBAHASAN DAN DAMPAK}

\section{Dusun Klapaloro I}

Dusun Klapaloro I merupakan sebuah Dusun yang terletak di pusat Desa Giripanggung, Kecamatan Tepus, Kabupaten Gunungkidul. Dusun ini terdiri dari 4 RT dan 112 Kepala Keluarga (KK). Batas wilayah di sebelah utara berbatasan dengan Dusun Palgading, sebelah timur berbatasan dengan Dusun Temuireng, dan sebelah selatan berbatasan dengan Dusun Gupakan, sedangkan di sebelah barat berbatasan dengan Klapaloro II. Mata pencaharian masyarakat di Dusun Klapaloro 1 sebagian besar yaitu petani, sehingga potensi yang menonjol di daerah tersebut adalah hasil bumi. Hasil bumi tersebut berupa kayu jati, ketela, jagung, kacang, padi, hingga sayur-sayuran. Selain itu, di Dusun Klapaloro I juga mempunyai Puskesmas pembantu yang berada di sebelah barat Balai Desa Giripanggung dan satu Mantri yang berada di RT 01.

Besar harapan dengan adanya 2 fasilitas kesehatan tersebut bisa membantu untuk menjaga kesehatan penduduk dan juga lingkungannya. Berada jauh dari kota, penduduk Dusun Klapaloro 1 ini sangat membutuhkan pengetahuan tentang kesehatan terutama tentang kesehatan reproduksi dan DBD (Demam Berdarah). Di Dusun Klapaloro banyak dijumpai anak-anak yang masih berada di masa pertumbuhan sudah berstatus nikah. Oleh sebab itu, dengan adanya mahasiswa KKN (Kuliah Kerja Nyata) di dusun tersebut dapat membantu dan memberikan pengetahuan tentang kesehatan reproduksi serta penyakit DBD.

\section{Dusun Klapaloro II}

Dusun Klapaloro II merupakan salah satu dusun yang berada di Desa Giripanggung yang terdiri dari 4 RT dengan batas-batas wilayah sebelah utara berbatasan dengan Dusun Klepu, sebelah selatan berbatasan dengan Dusun Gupakan, sebelah timur dengan Dusun Klapaloro I, sebelah barat Bolang, Giripanggung, Tepus. Total penduduk di Dusun Klapaloro II adalah 454 dengan proporsi laki-laki 220 orang dan perempuan 233 orang dengan jumlah 116 KK. Sebagian besa warga memiliki mata pencaharian bercocok tanam atau bertani.

Potensi sumber daya alam yang terdapat di Dusun Klapaloro II diantaranya adalah hasil bumi berupa hasil pertanian yaitu singkong, jagung, pisang, padi, cabai, kayu jati dan labu. Di Dusun Klapaloro II terdapat fasilitas pelayanan kesehatan seperti praktik mantri yang terletak di RT 04. Pelayanan Posyandu di Dusun Klapaloro II dilaksanakan satu bulan sekali setiap tanggal 10 yaitu berupa Posyandu balita.

\section{Dusun Bolang}

Dusun Bolang terletak di Desa Giripanggung, Kecamatan Tepus, Kabupaten Gunung Kidul. Luas wilayah Dusun Bolang adalah 61.178 Ha. Jarak desa ke pusat Pemerintah Desa yaitu kurang lebih 1,5 km. Total penduduk di Bolang adalah 439 oang dengan proporsi laki-laki 214 orang dan perempuan 225 orang. Sebagian besar warga 
memiliki mata pencaharian sebagai petani dan petenak. Setiap hari, masyarakat mencari rumput untuk hewan ternaknya. Pada siang hari, warga becocok tanam di ladang.

Dusun Bolang meupakan daeah yang subur syarat dengan potensi sumber pertanian antara lain: jagung, padi, terong, cabai, singkong, ubi, pohon jati, kacang tanah, pepaya dan labu. Beberapa ternak yang dimiliki warga adalah ayam kampung, kambing dan sapi. Untuk prasarana kesehatan di Dusun Bolang sudah tergolong memadai. Setiap bulan sekali dilaksanakan Posyandu balita.

Dusun Bolang yang merupakan dusun yang besar akan potensi untuk dijadikan desa yang kaya akan hasil pertaniannya namun terhambat oleh kurangnya kesadaran warga dan kurangnya keterampilan unruk mengolah hasil panen mereka. Diharapkan dengan adanya keberadaan Mahasiswa KKN ini bisa mampu mengatasi persoalan yang ada di Dusun Bolang.

\section{Pelaksanaan Progam Kerja}

Potensi wilayah yang tedapat di wilayah dusun Klapaloro II dan Dusun Bolang adalah tanaman singkong, sehingga hal tersebut melatarbelakangi mahasiswa KKN UAD mengadakan pelatihan pembuatan tepung mocaf. Tepung mocaf adalah tepung tebuat dari singkong yang sudah difermentasikan dan dapat digunakan untuk membuat berbagai macam olahan makanan.

Di pasaran harga tepung mocaf berkisar antara Rp 8.000,00-Rp 10.000,00 per kilogram. Harga tesebut tepaut jauh dari harga singkong pada umumnya maupun olahan singkong berupa tepung gaplek yang hanya berkisar antara Rp 1000,00-Rp 3000,00. Tepung mocaf memiliki daya jual yang cukup tinggi sehingga mampu membantu untuk mendongkrak perekonomian masyarakat di dusun tersebut.

Program kerja berikutnya adalah penyelenggaraan senam. Penyelenggaraan senam ini bertujuan untuk menarik minat masyarakat untuk berolahaga. Selain memperoleh tubuh yang sehat berolahraga mampu untuk mengembalikan keadaan psikis yang lelah saat melaksanakan rutinitas sehari-hari. Penyelenggaraan senam ini banyak dimintai oleh masyarakat terutama ibu-ibu dan remaja putri. Program ini dilaksanakan satu kali dalam seminggu.

Pelaksanaan penyuluhan kesehatan ini bertujuan untuk mengajak masyarakat untuk lebih peduli akan kesehatan fisik maupun kesehatan psikis. Program penyuluhan yang terlaksana diantaranya adalah penyuluhan mengenai penyakit demam berdarah, penyuluhan pola hidup sehat, dan penyuluhan kesehatan mental/jiwa.

Penyuluhan demam berdarah dilaksanakan dengan materi mengenai lingkungan hidup yang bersih dari jentik nyamuk, seta pembagian abate gratis untuk setiap warga. Materi penyuluhan pola hidup sehat memperkenalkan warga mengenai cara dan pola hidup yang sehat dengan menayangkan video mengenai pola hidup bersih dan sehat berawal dari diri sendiri serta tempat tinggal.

Penyuluhan kesehatan mental dengan materi mengenai kesehatan psikis pada remaja yang menikah pada usia muda/dini, pembagian leaflet mengenai pembangunan optimistik pada anak dan membangun kecerdasan emosi pada anak sejak dini, serta mengenalkan strategi coping stress kepada masyarakat. 
Diterbitkan oleh Lembaga Pengabdian kepada Masyarakat

Universitas Ahmad Dahlan Yogyakarta

Pendampingan posyandu dilaksanakan pada masing-masing dusun pada tanggal 10 setiap bulannya. Mahasiswa yang melaksanakan pencatatan administrasi peserta posyandu serta membantu untuk menyiapkan konsumsi sehat untuk peserta posyandu. Gambar aktivitas mahasiswa KKN UAD dan masyarakat Giripanggung tersaji pada gambar 1.

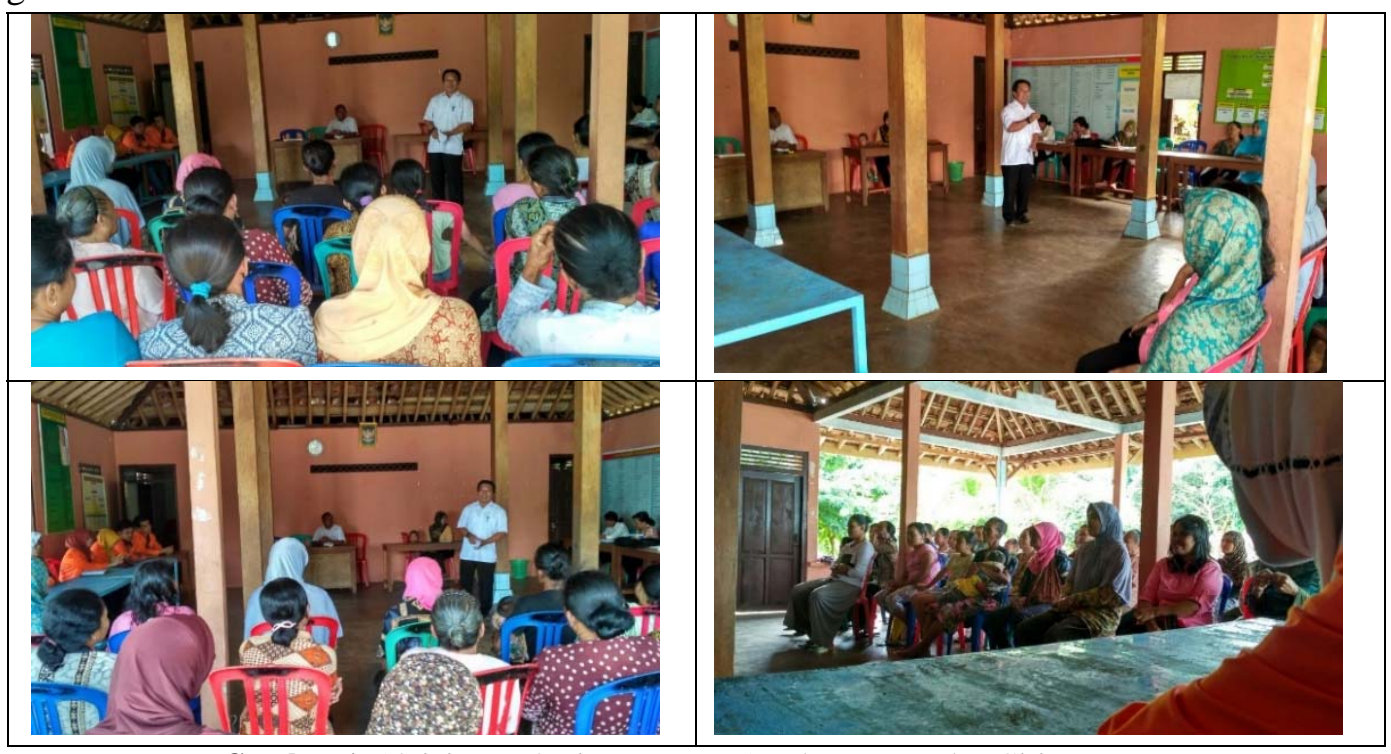

Gambar 1. Aktivitas mahasiswa KKN UAD dan masyarakat Giripanggung

Gambar 1 menunjukkan program KKN di Giripanggung dapat terlaksana dengan antusias dari masyarakat yang cukup tinggi. Oleh karena itu, dampak dari program ini adalah 1) meningkatkan pengetahuan dan tercipta kesadaran masyarakat bahwa potensi alam dapat dikembangkan sehingga singkong dapat diolah menjadi tepung mocaf dan memiliki nilai ekonomis yang lebih tinggi, 2) meningkatkan pengetahuan dan kesadaran masyarakat tentang pentingnya mendeteksi kesehatan baik fisik maupun mental sejak dini sehingga jika ada penyakit yang diderita dapat diketahui lebih awal dan segera mendapat pengobatan, 3) meningkatnya pengetahuan dan kesadaran masyarakat tentang pentingnya mengetahui tumbuh kembang anak melalui posyandu sehingga jika ada gejala kurang gizi dan lain-lain dapat segera diatasi.

\section{KESIMPULAN}

Berdasarkan pembahasan di atas dapat disimpulkan bahwa mahasiswa Universitas Ahmad Dahlan dalam pelaksanaan Kuliah Kerja Nyatan (KKN) bukan hanya mengabdi kepada masyarakat tetapi juga menerapkan ilmu yang sudah didapatkan selama kuliah. Serta dapat meningkatkan SDM dan SDA yang ada di masyarakat. Terlihat dari program kerja yang dilaksanakan oleh mahasiswa yang memiliki tema meningkatkan potensi wilayah dan kesehatan menuju Desa sejahtera. Dalam mewujudkan tema yang diusung, ketiga unit telah memiliki program tematik unggulan yang terdiri dari pelaksanakan pelatihan mocaf, penyuluhan kesehatan, pendampingan posyandu. 


\section{DAFTAR PUSTAKA}

Rogers, Everett M., 1983, Diffusion of Innovations. London: The Free Press.

Notoatmodjo, Soekidjo. 2003. Prinsip-Prinsip Dasar Ilmu Kesehatan Masyarakat. Jakarta: Rineka Cipta. 